\title{
ALİMÜNA İÇEREN NANOAKIŞKAN KULLANILARAK ISI BORULARININ PERFORMANSLARININ IYYİLEŞTİRİLMESİ
}

\author{
M. Tarık ÇAKIR \\ Sağlık Bakanlığı, İnşaat Onarım Daire Başkanlığı, 06590, Kurtuluş, Ankara \\ mutlutar@gmail.com
}

(Geliş/Received: 06.08.2014; Kabul/Accepted: 06.10.2015)

ÖZET

$\mathrm{Bu}$ çalışmada, termosifon (fitilsiz) tipi 1sı borusunda çalışma akışkanı olarak içerisinde hacimsel olarak \%2 $\mathrm{Al}_{2} \mathrm{O}_{3}$ (Alumina) nano partiküller bulunan nanoakışkan kullanılarak 1sıl performansın arttırılması amaçlanmıştır. $\mathrm{Bu}$ amaç için $13 \mathrm{~mm}$ çapında, $1 \mathrm{~m}$ uzunluğunda bakır borudan yapılmış 1sı borusu deney düzeneği hazırlanmıştır. Evaporatör bölgesi $40 \mathrm{~cm}$ uzunluğunda olup 1sı kaynağı olarak elektrikli spiral bir 1sıtıcı ile sarılarak dış bölgesi tamamen yalıtılmıştır. $20 \mathrm{~cm}$ adyabatik bölge ve diğer $40 \mathrm{~cm}$ kondenser bölgesidir. Kondenser etrafinda 1sının alınması için sürekli akışlı su soğutmalı bir paralel akışlı ısı değiştirici kullanılmıştır. Evaporatör ve kondenser bölgesine yerleştirilen dört noktadan sıcaklık ölçümleri yapılmıştır. Deneylerde kondenser bölümünde 1sının alınabilmesi için 3 farklı kütlesel debi $(5 \mathrm{~g} / \mathrm{s}, 7,5 \mathrm{~g} / \mathrm{s}$ ve $10 \mathrm{~g} / \mathrm{s})$ kullanılmış, evaporatör kısmında ise 1sı 3 farklı 1S1 $(200 \mathrm{~W}, 300 \mathrm{~W}$ ve $400 \mathrm{~W})$ girişi sağlanmış ve 1sı borusunun 2 farklı eğim açısı için deneyler yapıllmıştır. Çalışma akışkanının ısı borusu performansı üzerindeki etkileri deneysel olarak belirlenmiştir.

Anahtar Kelimeler: Isı borusu, nanoakışkan, alimüna

\section{IMPROVING THE EFFICIENCY PERFORMANCE OF HEAT PIPES USING ALUMINA CONTAINING NANO-FLUIDS}

\begin{abstract}
The present study aims to improve the efficiency of the heat pipe (without wick) using nano-fluid containing $\mathrm{Al}_{2} \mathrm{O}_{3}$ (alumina) nanoparticles at a concentration of $2 \%(\mathrm{v} / \mathrm{v})$. For this purpose, an experimental setup comprised of a copper pipe of $1 \mathrm{~m}$ length and $13 \mathrm{~mm}$ diameter was prepared. The evaporator section was $40 \mathrm{~cm}$ long. An electrical spiral heater was wrapped around that section as the heat source and the whole section was completely insulated. A $20 \mathrm{~cm}$ section was assigned as the adiabatic section and the remaining $40 \mathrm{~cm}$ of the pipe was the condenser section. A continuous parallel flow cooling heat exchanger was used around the condenser to remove heat from the system. Temperature measurements were made at four locations at the evaporator and the condenser sections. The transfer of heat from the pipe in the condenser section was determined using three different fluid mass flow rates $(5 \mathrm{~g} / \mathrm{s}, 7.5 \mathrm{~g} / \mathrm{s}$ ve $10 \mathrm{~g} / \mathrm{s})$ and the heat in the evaporator section was provided at three different power $(200 \mathrm{~W}, 300 \mathrm{~W}$ ve $400 \mathrm{~W})$ settings. The experiments were conducted by placing the setup at two different inclination angles. The effect of the working fluid on the efficiency performance of the heat pipe was thus experimentally determined.
\end{abstract}

Keywords: Heat pipe, nano-fluid, alumina

\section{GÍRIŞ (INTRODUCTION)}

Günümüzde enerji gereksiniminin artan nüfusa ve gelişen teknolojiye bağlı olarak artması, buna karşılık bir yandan enerji kaynaklarının kısıtlı olması, diğer yandan da enerji sağlanması ve kullanılmasında çevre sorunlarının getirdiği sınırlamalar, mevcut enerji kaynaklarının kullanımının yanı sıra yeni arayışları da beraberinde getirmektedir. Is1 enerjisinin bir ortamdan başka bir ortama aktarılmasında en önemli konu taşıma işleminin, en az güç harcanarak ve en verimli şekilde taşınmasıdır. Isı taşıyan pek çok sistem vardır. Isı boruları da 1sı taşıyan sistemlerden biridir [1]. Isı borusu ilk olarak Gaugler tarafindan 1944 yılinda 
yapılmıştır. Fakat ne yazık ki bu tarihlerde 1s1 değişimi için birçok klasik cihazın bulunması yüzünden bu buluş yeterli ilgiyi görmemiş ve uzun zaman unutulmuştur [2]. 1962 yılında Trefethen uzay araçlarında kullanılabilecek bir 1sı değiştiricisi fikrini ortaya atmıştır. Bu cihaz iç tarafinda gözenekli fitil bulunan boş bir borudan ibaretti. Fakat bu yıllarda bu fikri gerçekleştirmek için hiçbir deney yapılmamıştır [2]. 1964 yılında Grover ve arkadaşları bundan önce yapılan çalışmalardan habersiz olarak, Gaugler'in cihazına benzer 1sı değiştiriciyi keşfettiler ve adını 1S1 borusu (Heat Pipe) olarak zikretmişlerdir [3].

1964 yılından sonra 1sı borusu performansı üzerine çeşitli konularda çalışmalar yapılmıştır. Isı borularında performansı etkileyen bir etken olan 1S1 borusundaki 1sıl direnç; 1sı borusu içerisinde faz değişimi esnasında katı-sıvı ara yüzündeki buhar kabarcıklarının yapısıdır. Büyük boyuttaki kabarcık çekirdeği, katı yüzeyden sıvıya olan 1Sı transferini engelleyerek isıl dirence sebep olmaktadır [4].

Akışkan içerisine süspanse edilen partiküller akışkanın 1sıl kapasitesini büyütürler. Partiküller arasındaki etkileşim ve çarpışmalar akış geçiş yüzeyinin, çalkantı ve türbülans şiddetinin artmasına neden olur. Daha yüksek 1sı iletimiyle birlikte çalkantı şiddeti ve geniş yüzey alanı daha çok 1sı transferine izin verir. $20 \mathrm{~nm}$ den küçük partiküller atomlarının \% 20'sini yüzeylerine taşırlar, bu da onları ısıl etkileşim için hazır hale getirir. Diğer bir avantaj ise çok küçük boyutlarından dolayı sıvıda mikro taşınımı ortaya çıkaran ve bundan dolayı 1sı transferini artıran partikül hareketliliğidir[5].

$\mathrm{Su}$, motor yağı ve etilen glikoz (antifriz) gibi akışkanlar 1sı değiştiricilerde kullanılan geleneksel 1s1 transferi akışkanlarıdır. Bu geleneksel akışkanların 1sı transferi performanslarının düşük olması iyileşme veriminin az olmasina neden olmakta ve ayrica 1S1 değiştiricinin küçük boyutlarda ve az yer kaplayan geometride olmasını sınırlamaktadır. 1990'lardan beri, araştırmacılar 1Sı transferi alanına nano-malzeme teknolojisi uygulamaya başladı ve 1S1 transferi geliştirme üzerinde çok anlamlı sonuçlar elde edildi. Temel akışkan içerisindeki nano partiküller kabarcık oluşumu esnasında buhar kabarcıkları üzerine etki ederek çok daha küçük çekirdekleşmenin oluşmasını sağlamaktadır. $\mathrm{Bu}$ durum 1 sı borusu içerinde katı yüzeylerden sıvıya ısı geçişini kolaylaştırarak, 1S1 borularının 1sıl dirençlerinin düşmesine sebep olmaktadır. Ancak temel akışkanının içerisine karıştırılacak metalik malzemelerin boyutları bu işlem üzerinde son derece önemli bir etkiye sahiptir. Isıl direncin azaltılabilmesi için karışımlarda kullanılacak metalik malzemelerin 100nm'den daha küçük parçacık boyutunda olması gerekmektedir [5-6]. Literatürde pek çok çalışma da farklı metal ve metal oksitleri içeren nanoakışkanlar kullanılarak 1S1 borularının performans deneyleri yapılmıştır. Choi
(1995), metaller ( $\mathrm{Au}, \mathrm{Ag}, \mathrm{Cu}, \mathrm{Fe})$, metal oksitler $\left(\mathrm{CuO}, \mathrm{SiO}_{2}, \mathrm{Al}_{2} \mathrm{O}_{3}, \mathrm{TiO}_{2}, \mathrm{ZnO}, \mathrm{Fe}_{3} \mathrm{O}_{4}\right)$, ve karbürleri (SiC, TiC), Nitrürler (AlN, SiN) nanometrik partiküller halinde baz sıvı içinde süspansiyon oluşturarak "nanoakışkan" kavramını geliştirmişlerdir [7].

Chien ve diğ. (2003), düz plaka isı borusunda nanoakışkan uygulaması üzerine deneysel bir çalışma yapılmışlardır. Deneysel sonuçlar; nanoakışkan kullanılarak 1s1 borusu 1sıl direncinin farklı dolum oranlarda saf su kullanımına göre daha az olduğunu göstermiştir. Nanoakışkanların kullanımı ile 1sıl direncinde ortalama \% 40 azalma sağlanmıştır [9].

Wei ve diğ. (2005), nanoakışkan kullanan 1s1 borusunun 1sil direnci, saf su kullanilan 1si borusuyla karşılaştırıldığında \%28-44 oranında azaltıldığını tespit etmişlerdir [10].

Kang ve diğ.(2006) gümüş nanopartiküller ve saf sudan oluşan nanoakışkanlar kullanarak deneysel çalışmalar yapmışlardır. Gümüş nanoparçacık boyutları sırasıyla $10 \mathrm{~nm}$ ve $35 \mathrm{~nm}$ dir. Deneysel sonuçlar göstermiştir ki toplam 1sı direnci nanoparçacık konsantrasyonu ve nanoparçacık boyutunun artması ile azalmıştır. Saf su kullanılan 1sı borusuyla nanosivilar kullanarak 1s1 borusu karşılaştırıldığında ısıl direnci; 10nm nanopartiküller için $\% 50$ ve $35 \mathrm{~nm}$ için $\% 80$ oranında azalma olduğunu göstermektedir [11].

Liu ve Lu (2009) ve Yang ve diğ.(2008), su bazlı $\mathrm{CuO}$ nanoakışkan ve su bazlı karbon nanotüpler (CNT) çalışma sıvıları olarak kullanılmıştır. CuO nano sıvilar kullanarak ısı borusu 1sıl direnci üzerinde optimum \%1'lik konsantrasyon ve optimum $75^{\circ}$ eğim açısı da maksimum değerler elde edilmiştir [12-13].

Tsai ve diğ. (2004), silindirik örgü fitilli ısı borusu ile ilgili deneyler gerçekleştirmişler ve altın nanopartiküllerin sulu çözeltilerini kullanarak 1sı borusunun 1sıl direncinin \%20-37 azaldı̆̆ göstermişlerdir [14].

Liu ve Shu (2008), CuO-su karışımlı nanoakışkan kullanarak silindirik bir örgü fitil 1s1 borusunun 1S1 transferi özelliklerini incelemişlerdir. Isı borusunun 1sıl direnci, nanoakışkan kullanımında saf su kullanımına göre çok daha küçük olduğu belirlenmiştir [15].

Chen ve diğ. (2008), farklı güç girişlerinde (20-40 W) gümüş nanopartiküller ile su bazlı gümüş nanoakışkanlar kullanarak düz örgü fitil ısı borusunun performansını incelemişlerdir. Nanosıvılar kullanarak 1S1 borusunun 1sil direnci saf su kullanilan 1s1 borusu ile karşılaştırıldığında azalma gözlemlenmiştir [16]. Kang ve diğ.(2009), silindirik sinterlenmiş fitilli isı 
borusunun 1sıl direncini incelemişlerdir. Isı borusu bakır tozlarından yapılmış bir $1 \mathrm{~mm}$ kalınlığında sinterlenmiş-fitil içermektedir. Deneyde; 10nm ve 35nm parçacık boyutlarına sahip olan gümüş nanopartiküller ve saf su kullanılmıştır. Deneysel sonuçlarda 1sıl direnç, $60 \mathrm{~W}$ 1sı yükü için $\% 88$ azalmıştır [17].

Shang ve diğ. (2007) farklı dolum oranları altında akışkan olarak $\mathrm{Cu}$-su nanoakışkan ile bir kapalı devre titreşimli 1S1 borusunun 1S1 transferi özelliklerini incelemişlerdir. Akışkan olarak damıtılmış su ile nanoakışkanın karşılaştırılması sonucunda; 1s1 borusunun $\mathrm{Cu}-\mathrm{su}$ nanoakışkanların kullanımı \%83 daha fazla 1sı aktarma kapasitesini arttırdığı ortaya koyulmuştur [18].

Qu ve diğ. (2010), kapalı devre titreşimli 1sı borusunda su bazlı $\mathrm{Al}_{2} \mathrm{O}_{3}$ nanoakışkan kullanımının termal performansında oluşturacağı etkiye dair deneysel bir çalışma yapmışlardır. Deneysel sonuçlarda 1 sıl direncin $\% 32.5$ azaldığını tespit etmişlerdir [19].

Xue ve diğ.(2006), kapalı iki fazlı termosifonda karbon nanotüp (CNT) kullanımının termal performansı üzerine etkisi hakkında araştırma yapmışlardır. Deneysel sonuçlarda CNT kullanarak 1sı borusunun 1sıl direnci su kullanılan 1s1 borusu göre daha yüksek olduğu ve baz sıvıya CNT ekleyerek 1sı borusunun termal performansinın negatif yönde etkilendiğini tespit etmişlerdir [20].

Liu ve diğ. (2007), iki fazlı termosifonda $\mathrm{CuO}$ nanoparçacık kullanılmasının termal performansa etkisini incelemişlerdir. Deneysel sonuçlar, 1S1 borusunun nanoparçacık ilavesiyle 1Sı transferi ve kritik 1sı akısının da arttırılabileceğini göstermiştir [21-22].

Khandekar ve diğ. (2008), su ve su bazlı Al2O3 ve $\mathrm{CuO}$ içeren nanoakışkanlar kullanarak kapalı iki fazlı termosifonun isıl direncini araştırmışlardır. Deney sonuçlarına göre, nanoakışkanın kullanımının su kullanımına nazaran termal performansina etkisi negatif olmuştur [23].

Naphon ve diğg. (2008), titanyum-etanol nanoakışkanlar ve titanyum-su nanoakışkanlar kullanarak kapalı iki fazlı termosifon arasında 1s1 transferi performansı araştırmışlardır. Buharlaşma 1sı aktarım katsayısı; nanoakışkan kullanımında etanol kullanımına göre karşılaştırıldığında \%10.6 artmıştır[24].

Noie ve diğ. (2009), $\mathrm{Al}_{2} \mathrm{O}_{3}-\mathrm{Su}$ nanoakışkanının 1s1 borusundaki performansını araştırmışlardır. \%3 $\mathrm{Al}_{2} \mathrm{O}_{3}$-Su karışımlı nanoakışkanın 1sı borusunda saf su ve diğer karışım oranlarına göre daha iyi performans verdiğini tespit etmişlerdir [25].
Huminic ve diğ.(2011), termosifon 1sı borusunda saf $\mathrm{su}$ ve $\% 2 \sim \% 5.3$ konsantrasyonundaki $\mathrm{Fe}_{2} \mathrm{O}_{3}$ nanoakışkanlarıyla deneyler yapmışlardır. Elde edilen sonuçlara göre \%5.3 derişimdeki nanoakışkan kullanıminda suya göre termal performansta iyileşmeler gözlemlenmiştir [4].

$\mathrm{Bu}$ çalışmada; literatürden farklı olarak ortalama partikül çap1 $10 \mathrm{~nm}$ olan $\% 2 \quad \mathrm{Al}_{2} \mathrm{O}_{3}$ (alümina) konsantrasyonunda saf su içerisine \% 0.2 Triton X-100 yüzey aktifleştirici kullanılarak ultrasonik banyoda yaklaşık 8 saat karıştırılarak elde edilen nanoakışkan 1Sı borusunda çalışma akışkanı olarak kullanılmış ve termal performansın iyileştirilmesi amaçlanmıştır. Triton X-100 yüzey aktifleştirici sayesinde literatürde çok sık rastlanan nanoakışkanın topaklanması ve isı borusu üzerine yapışması önlenmiştir. Yüzey aktifleştirici oranı farklı olan çözeltiler hazırlanarak çökelme ve topaklanma açısından gözlenmiş olup optimum oranın $\% 0.2$ olduğu görülmüştür. Deneysel çalışmada farklı evaporatör 1sı yükleri ve farklı kondenser soğutma suyu debileri için 1sı borusu boyunca sıcaklık değişimleri ve termal performans değerleri ölçülmüştür.

\section{ISI BORUSU (HEAT PIPE)}

Isı borusu, küçük kesit ve yüzeylerden çok büyük miktarlarda 1sı geçişine olanak sağlayan bir cihazdır. Sistem iç tarafindan tabaka halinde bir fitil malzemesi ile kaplanmış içi boş silindir bir borudan oluşmaktadır. Boru içinde aynı zamanda yoğuşabilen bir akışkan vardır. Akışkanın sıvı fazı kılcal olay yardımıyla fitil içinde hareket edebilmektedir. Buharlaştırıcı adı verilen borunun bir ucuna 1sı verildiğinde, fitil içindeki akışkan buharlaşır ve buharlar borunun orta k1sminda hareket ederler. Yoğuşturucu denilen borunun diğer kısmından 1s1 çekilirse bu bölgede buharlar yoğuşarak sıvı faza geçer ve sıvı fitil içinde kılcal olay dolayısıyla tekrar buharlaştırıcı kısmına geri döner. Boyuna doğrultuda 1sı borusu buharlaştırıcı ve yoğuşturucu bölgelerinden meydana gelmiştir. Ayrıca buharlaştırıcı ve yoğuşturucu bölgeleri birbirinden ayırmak için ikisi arasında üçüncü bir yalıtılmış bölge vardır [2]. Cihazın çalışma şeması Şekil 1 de görülmektedir.

Bir 1s1 borusu, 1sıyı vakumlu bir metal boruyla bir noktadan diğer bir noktaya taşır. Boru, genelde \%90'1 su, geri kalan kısmı 1sı transferini optimize edecek maddeler olan bir sıvı içerir. Isı borusu (Heat-pipe), 1S1 iletimini iyileştirmeye yarayan bir yöntemdir. Isı borusu yönteminde; 1S1, içinde kimyasal madde olan bir boru aracılığıyla soğutma yapılacak noktaya iletilir. Isı borusu, vakum prosesi uygulanmış, iç yüzeyleri gözenekli kılcal fitil ile kaplanmış kapalı boru veya farklı şekilli odalardır. Fitil bulunmayan 1sı boruları termosifon olarak adlandırılır. 


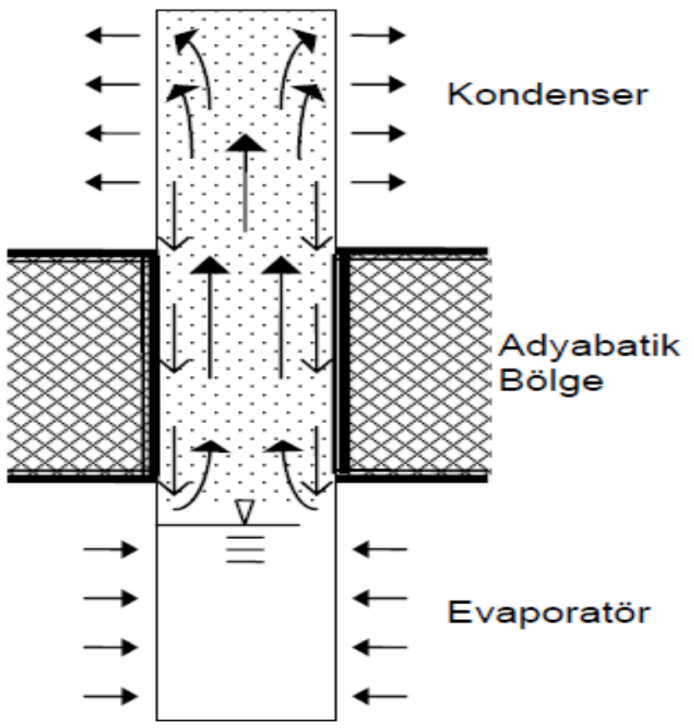

Şekil 1. Isı borusunun çalışma şeması (Heat pipe operating schema)

\subsection{Deney Düzeneği (Testing Apparatus)}

Deneysel çalışmalar farklı aşamalardan meydana gelmektedir ve ilk adımını nanoakışkanın hazırlanması oluşturmaktadır. Deneysel çalışmada kullanılan nano partiküller alüminyum oksittir $\left(\mathrm{Al}_{2} \mathrm{O}_{3}\right)$. Temel akışkan olarak ise saf su kullanılmıştır. Isıl iletkenliği bilinen $\mathrm{Al}_{2} \mathrm{O}_{3}$ saf suyun içerisine $\% 2$ hacimsel oranda ortalama $10 \mathrm{~nm}$ boyutunda nanopartikül ilave edilerek elde edilen süspansiyon ultrasonik banyoda 4 saat karıştırılmıştır. Ayrıca karışıma yüzey aktifleştirici olarak \%0.2 oranında Triton X-100 ilave edilmiştir. $\mathrm{Bu}$ işlem sonucu elde edilen nanoakışkanın 1sıl özellikleri Tablo 1'de verilmiştir. Deney düzeneğinin şematik resmi Şekil 2'de görülmektedir. Deney düzeneğinde istenilen bölgelerin anlık sıcaklık değerlerinin ölçümü için 10 adet 1 șl çift, akış kontrolü için debimetre, vakum işlemini gözlemleyebilmek için manometre, akışkanın doldurulması için doldurma musluğu ve güç kaynağı bulunmaktadır. Veri toplama için bir adet bilgisayar, data logger kullanılmıştır (Şekil 3-4).

Tablo 1. \%2 derişimindeki alümina nanoakışkanının termal özellikleri (Thermal characteristics of $2 \%$ concentration alümina nanofluids )

\begin{tabular}{||l|l|l||}
\hline \hline Yoğunluk $(\mathrm{d})$ & $\mathrm{kg} / \mathrm{m}^{3}$ & 1056.1384 \\
\hline Özgül Is1 $\left(\mathrm{C}_{\mathrm{p}}\right)$ & $\mathrm{j} / \mathrm{kgK}$ & 3931.5972 \\
\hline Isıl İletkenlik $(\mathrm{K})$ & $\mathrm{W} / \mathrm{mK}$ & 0.62337083 \\
\hline
\end{tabular}

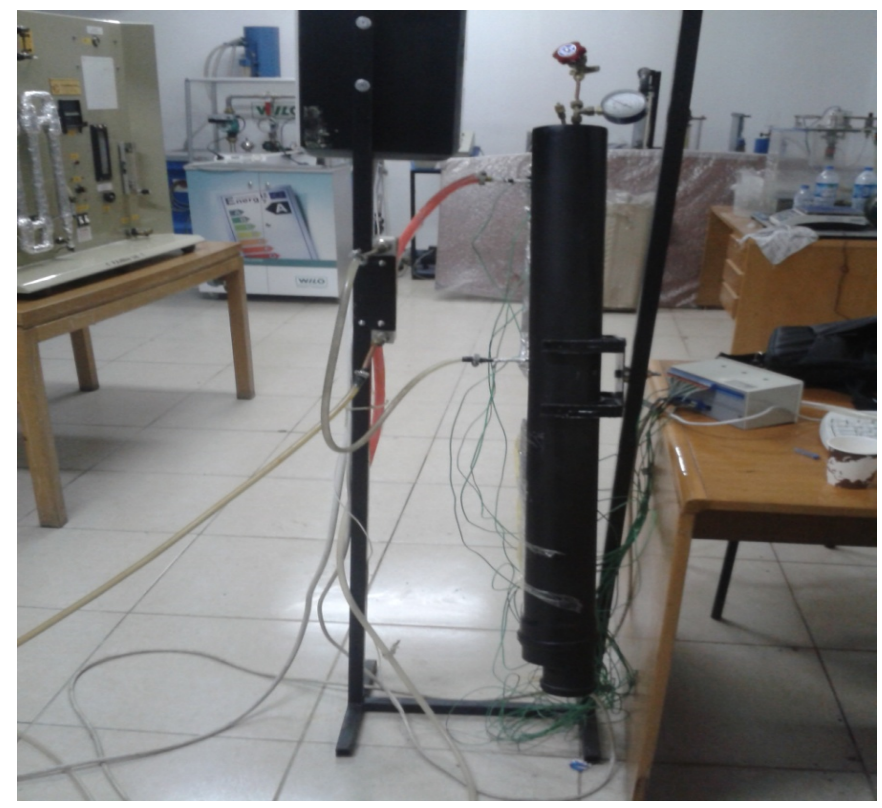

Şekil 2. Isı borusunun deney düzeneğinin görünümü (Schematic diagram of heat pipe testing apparatus) 


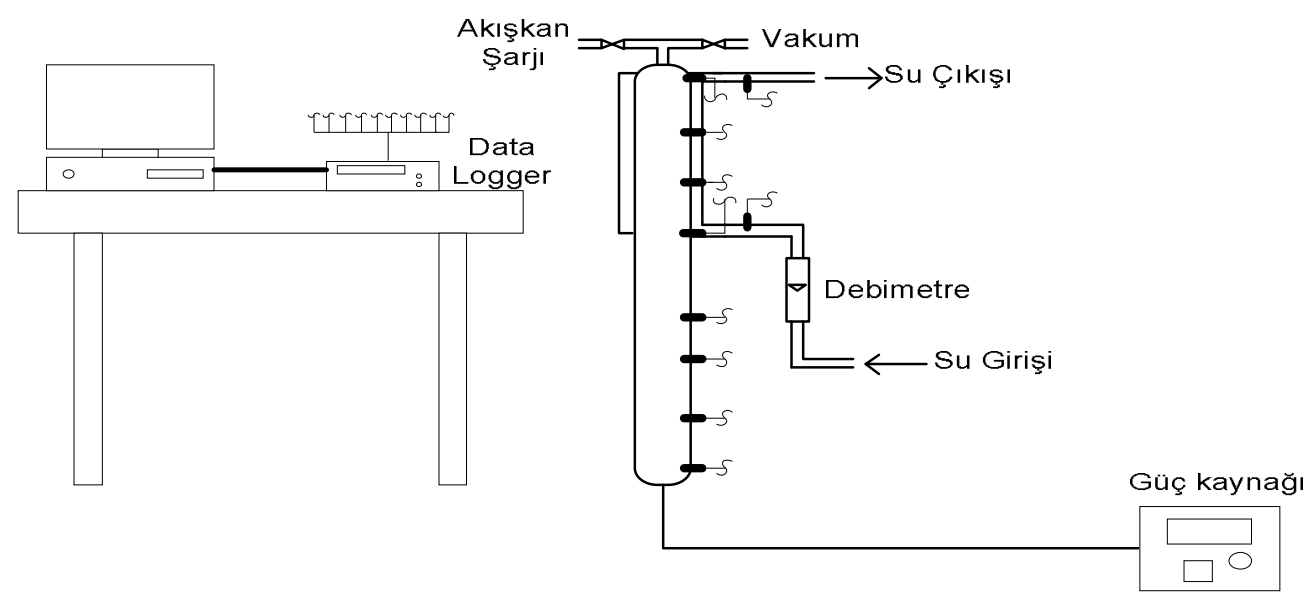

Şekil 3. Deney Düzeneğinin Şematik Gösterimi (Schematic diagram of testing apparatus)

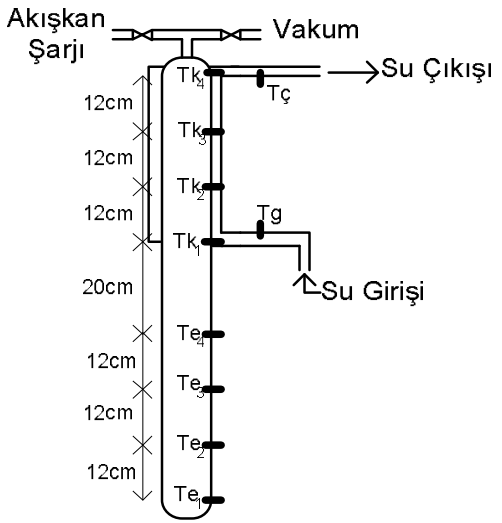

Şekil 4. Isı borusunda isılçift yerleşimi (Lay-out of thermocouples on heat pipe)

Deney düzeneği; 1 adet 1sı borusu, ladet debimetre, 1 adet manometre, 10 adet 1 silçift, 1 adet data logger, doldurma vanası, güç kaynağı ve bilgisayardan oluşmaktadır.

\section{NANOAKIŞKAN TEKNOLOJISİ (NANO-FLUID TECHNOLOGY)}

Isı transferi cihazları üzerinde ki mevcut araştırma ve gelişim çabalarına rağmen klasik 1sı transfer akışkanlarının düşük ısıl iletkenliği bu cihazların performansları üzerinde önemli kısıtlamalara neden olmuştur. Oda sıcaklığındaki bakırın 1sıl iletkenliği suyunkinden yaklaşık 700 kat, motor yağınkinden 3000 kat daha büyüktür.

Metal akışkanların 1sıl iletkenlikleri ametal akışkanlarınkinden çok daha fazladır. Bu nedenle katı partikül içeren akışkanların 1sıl iletkenliklerinin geleneksel akışkanların 1sıl iletkenliklerinden daha yüksek olması beklenir [31].

Sıvıların içerisine katı tanecik ekleyerek 1Sı transfer özelliğini iyileştirme çabaları çok daha önceleri de denenmiş bir yöntemdir, fakat büyük boyutlu katı taneler ancak yüksek hacimsel katkı oranlarında 1 sıl özelliklerde çok düşük oranda bir iyileşme sağlarken; taneciklerin çökelmesi, sistemde parçaların aşınması ve basınç düşümü gibi olumsuzluklar nedeniyle istenilen sonuçları vermemekteydi. Üstelik gittikçe küçülen ısı değiştirici elemanların ve mikrokanalların bu mikrotanecik katkılı akışkanlar ile tıkanması mikro boyutlu taneciklerin kullanımını imkânsız kılmaktadır [5].

Arganne National Laboratory'de Choi tarafindan nano boyuttaki partiküller temel akışkan içine karıştırılarak 1s1l özellikleri iyileştirilmişstir. Isıl iletkenlikleri yüksek nano boyuttaki katı partiküllerin (bakır, gümüş, alüminyum vs.) klasik ısı transferi akışkanının içine katılmasıyla elde edilen yeni 1sı transferi akışkanına "nanoakışkan" denilmektedir. Nanoakışkan; temel akışkan ve nanopartikülden oluşan süspansiyon olarak tanımlanabilir. Katı bir metalin ısıl iletkenliği temel akışkanınkinden yüksek olduğu için temel akışkan içerisine katılan nano boyuttaki katı metaller; akışkanın 1sıl iletkenliğini, taşınım özelliklerini ve 1S1 transferi performansını değiştirir [7]. Dünya genelindeki nanoakışkan araştırma gruplarından elde edilen araştırma sonuçları, nanoakışkanların bilinen ısı geçişi akışkanlarının sahip olduğundan çok farklı 1sıl özelliklere sahip olduğunu göstermektedir. Bir çalışmada bilinen 1sı geçişi akışkanlarına küçük miktarda(hacim konsantrasyonu \%1'den daha az) nanoparçacık eklenmesi, akışkanların isıl iletkenliğini hemen hemen iki katına kadar arttırmıştır [32].

\subsection{Nanoakışkanların Hazırlanması (Nano-fluid Preparation)}

Nanoakışkanlar basit katı-sıvı süspansiyonu değildir. Sıvı içerisine partikül ilave edilmesiyle elde edilen yeni akışkan aşağıdaki özellikleri sağlamalıdırlar.

- Kararlı (stabil) ve dayanıklı (durabil) bir süspansiyon oluşturmalıdır.

- Partiküllerdeki topaklanma ihmal edilebilir düzeyde olmalidir.

- Akışkanın kimyasal özelliklerini değiştirmemelidir [5]. 
Nanoakışkanlar nano boyutlarda katı partiküllerin temelde su, etilen glikol veya yağ gibi akışkanlara katılması ile hazırlanırlar. Nanoakışkan hazırlanmasında iki metot kullanılmaktadır.

1. Tek adım metodu

2. İki adım metodu

Tek adım metodu olarak bilinen yöntemin ana fikri temel akışkan içerisinde nano partikül üretimidir. İki adım metodunda önceden hazırlanmış olan nano partiküller temel akışkan içerisine uygun yöntemlerle karıştırılarak süspansiyon oluşturulur. Tek adım metodu ile karşılaştırıldığında iki adım metodu metalik partiküller için daha az uygun olmasına karşın oksit partikülleri için iyi sonuç vermektedir [33].

Genelde nanoakışkan süspansiyonu hazırlanırken kullanılan yöntemler üç türlüdür [34]:

- Süspansiyonun pH değerini değiştirmek.

- Yüzey aktivitörleri ve /veya seyrelticiler kullanmak.

- Ultrasonik titreşimler kullanmak.

Homojen partikül dağılımının sağlanması ve topaklanmanın azaltılması için ultrasonik ekipman kullanımının dışında yüzey aktivatörleri eklenmesi ve pH kontrolü gibi metotlarda kullanılmaktadır. Tüm bu teknikler, kararlı bir süspansiyon elde etmek için partiküllerin kümelenmesini ortadan kaldırmayı ve asılı partiküllerin yüzey özelliklerini değiştirmeyi amaçlamaktadır. Nanoakışkan süspansiyonlarında en büyük problem topaklanmadır. Topaklanmayı önlemek için partiküllerin ve çözeltilerin özelliklerine bağlı olarak süspansiyona uygun bir yüzey aktivatörü veya seyreltici çok az miktarda ilave edilmektedir. Genelde kullanılan aktivatörler ve seyrelticiler thioller, oleik asit ve laurate tuzlarıdır [35]. Seyrelticilerin eklenmesi özellikle yüksek sıcaklıklarda nanoakışkanların 1Sı transferi performansını etkilemektedir. Boru içindeki aşınma ve basınç düşümü problemleri düşük partikül hacim oranları kullanılarak (genellikle $\% 5$ den az hacimsel oranlarda) büyük ölçüde azaltılmaktadır [5].

\subsection{Nanoakışkanların Isıl İletkenlikleri (Thermal Conductivity of Nano-fluids)}

Isıl iletkenlik akışkanın 1s1 transferi performansını arttırmada önemli bir parametredir. Katı metallerin 1sıl iletkenliğinin akışkanların ısıl iletkenliğinden daha yüksek olduğu için, süspanse edildiği akışkanın 1sıl iletkenliğini ve 1sı transferi performansinı arttırabileceği düşünülmektedir [5].

Nanoakışkanların ısıl iletkenliği hem partikülün hem de temel akışkanın isıl iletkenliğine bağlıdır ve nanopartiküllerin hacimsel oranının artışıyla artar. Nanoakışkanın 1sıl iletkenliği nanoakışkanın viskozitesine, temel akışkanın 1sıl iletkenliğine, katı partikülün özelliklerine (yoğunluğu, gizli 1sısı gibi) ve nanopartikülün hacimsel oranına bağlıdır. Nanoakışkanın 1sıl iletkenliği nanopartikül kümesinin dönme yarıçapıyla ve topaklanmanın oransal yapısıyla değişir. Akışkan içerisine süspanse edilmiş kümelerin dönme yarıçapı ne kadar küçükse nanoakışkanların 1sıl iletkenliği o kadar büyük olur. Çünkü daha küçük kümeler birim zamanda daha hızlı ve daha uzağa hareket ederler ve nanoakışkan içerisinde daha güçlü enerji taşınımına neden olurlar [35].

Tüm bu faktörler dikkate alınarak nanoakışkanların 1sıl iletkenliği;

- Hem temel akışkanın hem de nanopartikülün ısıl iletkenliği,

- Hacimsel oran,

- Yüzey bölgesi,

- Sıv1 içerisine süspanse edilmiş nanopartiküllerin biçimi,

gibi parametrelerinin fonksiyonu olarak artar [5].

\subsection{Nanoakışkan Hazırlanması (Preparation of nanfluid)}

Ticari olarak satılan alümina nano parçacıkları istenilen nano boyutta olmadığı için Spex-8000 (Spex Industries, Inc., Edison, NJ) tipi bilyeli öğütücü ile ortalama $10 \mathrm{~nm}$ 'e getirilmiştir. Hazırlanan saf su içerisine $\% 2$ oranında alumina nanopartikülleri ilave edilmiştir. Yüzey aktifleştirici olarak hazırlanan süspansiyon içerisine $\% 0,2$ oranında Triton X-100 yüzey aktifleștirici katılarak 8 saat süreyle ultrasonic banyoda (Bandelin Sonorex Super RK514H) karıştırılmıştır. Bu çalışmayı diğerlerinden ayıran iki temel özellik bulunmaktadır. Bunlardan biri nanopartikül tanecik boyutunun literatürdekinden çok daha düşük hale gelmiş olması diğeri ise kullanılan yüzey aktifleştiricinin nanoakışkanın çökelme ve topaklanma problemini çözmesidir. Kullanılan yüzey aktifleştirici Triton X-100 orjinalinde ticari olarak Rohm \& Haas Co tarafindan üretilmekte olup daha çok deterjan endüstrisinde kullanılmaktadır. Triton $\mathrm{X}$ 100 kimyasal olarak $\left(\mathrm{C}_{14} \mathrm{H}_{22} \mathrm{O}\left(\mathrm{C}_{2} \mathrm{H}_{4} \mathrm{O}\right)_{n}\right)$ ifade edilir. Jelleşerek bir kayganlık sağlar ve temas açısını düşürür.

Temel akışkan-nanopartikül karışımının homojen bir şekilde karışması ve kararlı olabilmesi için uygulanan yöntemlerden biri karışımı bir süre ultrasonik titreşime maruz bırakmaktır. Deneysel çalışmada kullanılan Ultrasonik Banyonun teknik özellikleri aşağıdaki gibidir (Şekil 5).

- Voltaj: $230 \mathrm{~V}-50 \mathrm{~Hz}$

- Ultrasonik Gücü: 600 peak/300 Watt

- Isitıcı Gücü: 500 Watt

- Ultrasonik Frekansı : 28 kHz 


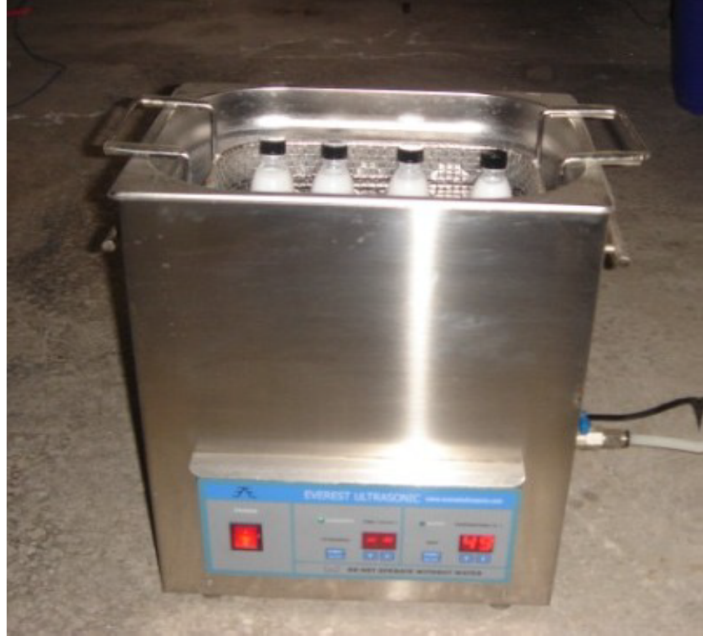

Şekil 5. Ultrasonik Banyo (Ultrasonic bath )

\subsection{Deney Prosedürü (Testing Procedure)}

Deneyler önce saf su ile sonra \%2 oranındaki $\mathrm{Al}_{2} \mathrm{O}_{3}$ süspansiyonu ile yapılmıştır. Isı akışı sağlanacak olan akışkan kondensere 3 faklı $\left(\mathrm{m}_{1}=0,005 \mathrm{~kg} / \mathrm{s}\right.$, $\mathrm{m}_{2}=0,0075 \mathrm{~kg} / \mathrm{s}$ ve $\left.\mathrm{m}_{3}=0,01 \mathrm{~kg} / \mathrm{s}\right)$ debide verilmiştir. Sisteme 300W, 400W, 500W'lık farklı 1sı enerjileri eveparotörden aktarılmıştır. Yapılan her deneyde 20 dakika süren kararlı hale ulaşma süresinden sonra veriler kaydedilmiş, akış şartları bir alt debi değerine ayarlanmış ve son debi değerine kadar deneyler tekrarlanmıştır. Isı borusunun $45^{\circ}$ ve $75^{\circ}$ 'lik eğim açıları için aynı işlemler tekrar yapılmıştır. Evaporatöre 1sı girişi $\mathrm{Ni}-\mathrm{Cr}$ spiral tipi 1sıtıcı ile sağlanarak güç kontrolü sayesinde sabit ısı çalışma akışkanına aktarılmıştır. Aktarılan 1sı wattmeter (Fluke-43b analyzer) ile kaydedilmiştir. Kondenserde kullanılan debi metre $\pm 0.01 \mathrm{~g} / \mathrm{s}$ hassasiyetlidir.

\subsection{Teorik Analiz (Theoretical Analysis)}

Kondenserde soğutma suyu vasitasıyla çekilen 1sı miktarı Eş. 1'de verilmiştir. Soğutma devresinde su kullanılmaktadır. Suyun giriş ve çıkış sıcaklığ 1 termokpul vasitasıyla ölçülmüştür.

$\dot{Q}_{c}=\dot{m}_{c} \cdot c_{p} \cdot\left(T_{o u t}-T_{\text {in }}\right)$

Evaporatörde elektrikli 1sıtıcı vasıtasıyla çalışma akışkanına verilen isı ile kondenserde soğutma suyu tarafından çekilen isı yardımıyla 1sı borusunun verimi Eş. 2 deki bağıntı ile hesaplanır.

$\eta=\frac{\dot{Q}_{c}}{\dot{Q}_{e}}=\frac{\dot{Q}_{\text {out }}}{\dot{Q}_{\text {in }}}$

Burada $\dot{Q}_{\text {e }}$ sisteme verilen 1sıdır (200W, 300W and $400 \mathrm{~W})$. Evaporatör tamamen yalıtıldığ 1 için verilen ısının tamamının çalışma akışkanına aktarıldığı kabul edilmiştir.
Isı borusunun termal direnci ise Eş.3 kullanılarak hesaplanabilir:

$R=\frac{\Delta T}{\dot{Q}_{\text {in }}}$

Burada $\dot{Q}_{\text {in }}=\dot{Q}_{\text {e }}$ olup $\Delta \mathrm{T}$ evaporator bölgesinde dört termokpul ile ölçülen sıcaklığın ortalaması ile condenser bölgesinde ölçülen dört sıcaklığın ortalaması arasındaki farktır ve Eş.4'de verilmiştir.

$\Delta T=\left(\frac{T_{e 1}+T_{e 2}+T_{e 3}+T_{e 4}}{4}\right)-\left(\frac{T_{c 1}+T_{c 2}+T_{c 3}+T_{c 4}}{4}\right)$

\subsection{Belirsizlik Analizi (Uncertainty Analysis)}

Deneysel sonuçların belirsizlik değerleri deney parametrelerinin diferansiyeline bağlı olarak ölçülür. Yapılan deneysel çalışmalar üç kez tekrarlanarak aşağıdaki Eş.5'deki bağıntıdan hesaplanmıştır.

$U_{m}=\sqrt{\frac{\Delta T}{T}+\frac{\Delta Q}{Q}+\frac{\Delta \dot{m}}{\dot{m}}}$

Termokpul ile ölçülen sıcaklığın, debimetrenin ve wattmetrenin ölçme hassasiyetleri sırasıyla $\pm 0,5{ }^{\circ} \mathrm{C}$, $\pm 0,01 \mathrm{~g} / \mathrm{s}$ and $\pm 1 \mathrm{~W}$, bulunmuştur. $\mathrm{Bu}$ değerlerle deney düzeneğinin ölçme belirsizliği $\pm 3 \%$ arasındadır.

\section{DENEYSEL SONUÇLAR (EXPERIMENTAL RESULTS)}

Çalışmanın amaçları, 1sı borularında çalışma sıvısı olarak kullanilan saf su yerine, $\mathrm{Al}_{2} \mathrm{O}_{3}$ nano malzeme içeren daha yüksek ısı depolayabilme ve taşıyabilme özelliklerine sahip nano malzeme-saf su karışımı nanoakışkan geliştirilmesi ve bu nanoakışkan kullanımı ile,

- Çalışma sıvısının yüzey gerilimi azaltılarak 1S1 borusunun isıl direncini düşürmek,

- Evaporatör ve kondenser bölgeleri arasındaki oldukça düşük sıcaklık farklarında 1S1 iletim miktarını arttırmak,

- Isı borusu performansinı arttırmaktır.

Isı değiştiricilerde nanoakışkan kullanımının amaçlarından biri olan düşük 1sı farklarında bile yüksek 1sı aktarımı sağlamaktır. Farklı açılardaki 1sı borusu eğimlerinde elde edilen ısıl direnç değerleri, $45^{\circ}$ için Şekil 6' da $75^{\circ}$ için Şekil 7'de verilmiştir.

Nanoakışkan kullanımı ile 1sı borusunun 1sıl direnci $45^{\circ}$ eğimli 1sı borusu için 0,07 seviyelerinde iken saf su kullanımında 0,13 civarındadır. Nanoakışkan kullanımı ortalama olarak \%46 1sil direncin azalmasına neden olmuştur. Benzer durum 1S1 borusunun $75^{\circ}$ eğimi içinde elde edilmiştir (Şekil 7). 


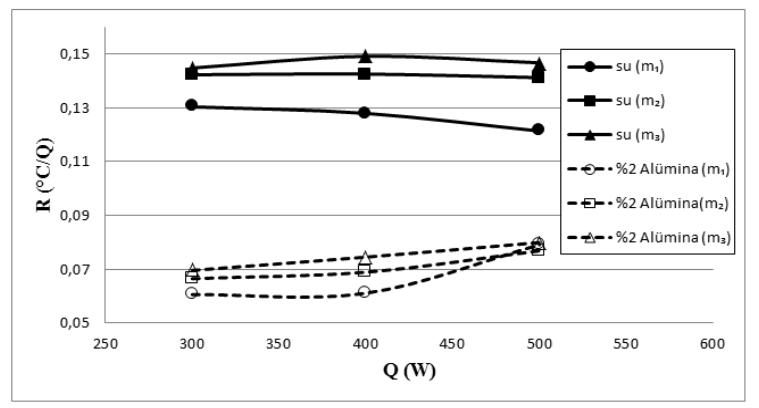

Şekil 6. $45^{\circ}$ lik $1 \mathrm{~S}$ i borusu açısıyla elde edilen 1 sil direnç grafiği (The thermal resistance figure getting from $45^{\circ}$ heat pipe angle)

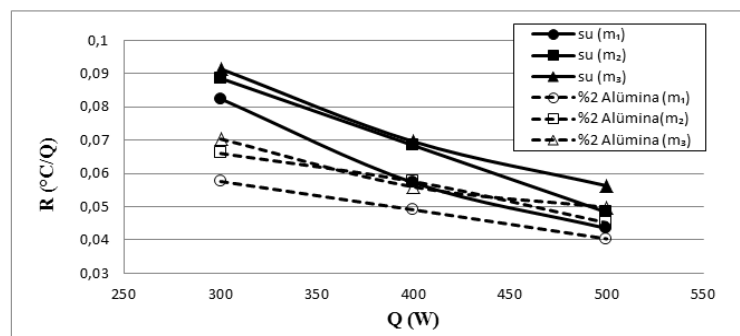

Şekil 7. $75^{\circ}$ lik isı borusu açısıyla elde edilen 1 șl direnç grafiği (The thermal resistance figure getting from $75^{\circ}$ heat pipe angle)

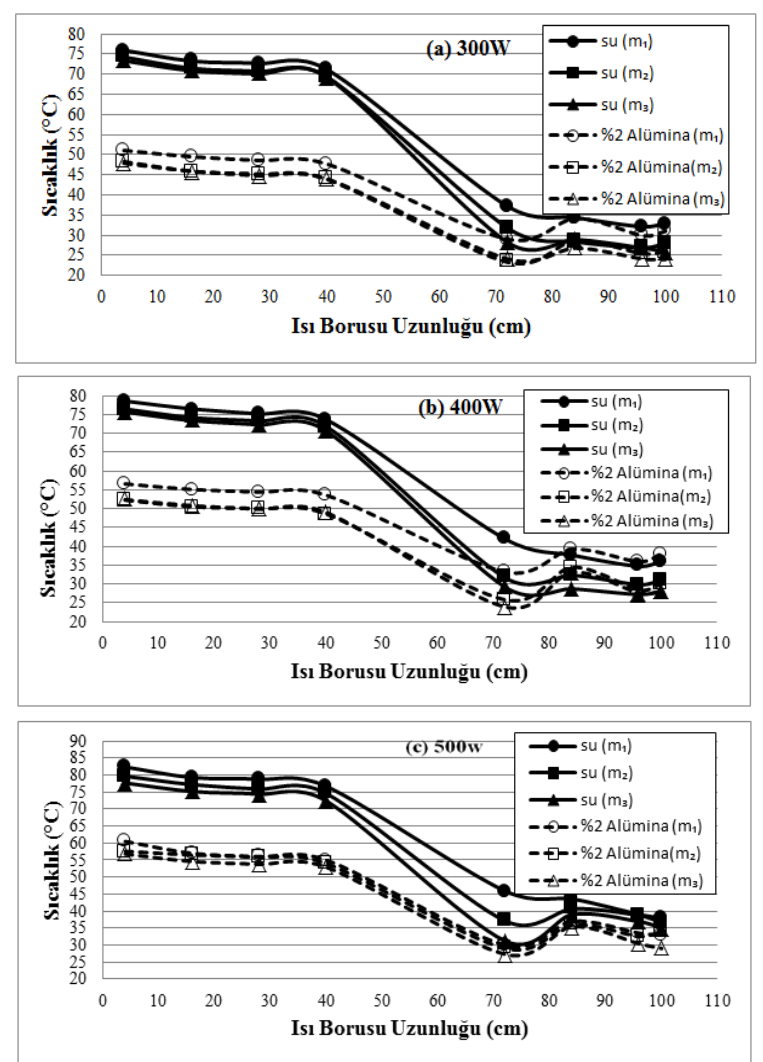

Şekil 8. (a-c) Nanoakışkan ve saf su kullanılan $45^{\circ}$ lik eğime sahip 1sı borusunun belirli noktalarından ölçülen ortalama sıcaklıkların karşılaştırılması ((a-c) Comparison of mean temperature measuring from specific point in heat pipe having $45^{\circ}$ slope using nano-fluid and water)

Isı direncin azalmasına neden olan nanoakışkan ile çalışan 1Sı borusunda çalışma akışkanın 1sıyı absorplayarak daha düşük sıcaklıkta buharlaşması ve bu suretle $\Delta \mathrm{T}$ sıcaklık farkının düşmesidir. Daha düşük sıcaklıkta nanoakışkanın buharlaşması Şekil 8 a-c'de farklı ısı yükleri için verilmiştir. Saf su 1sı borusunda vakum altında $75-80^{\circ} \mathrm{C}$ evaporatör sıcaklığında buharlaşırken nanoakışkan kullanılan isı borusunda $45-50^{\circ} \mathrm{C}$ 'larda buharlaşma sağlanmıştır. Bu da 1sıl direnci düşürmektedir.

$75^{\circ}$ eğimli 1sı borusu için ölçülen sıcaklıklar da ise $45^{\circ}$ ye göre bir $\Delta \mathrm{T}$ sicaklık farkında azalma görülmüştür. Dolayısıyla ısıl dirençteki kazanç $45^{\circ}$ ye daha düşük olmuştur. 750 eğimli 1 sı borusu için ölçülen sıcaklıklar ise Şekil 9 a-c'de farklı ısı yükleri için verilmiştir. $45^{\circ}$ eğimli $1 \mathrm{~S} 1$ borusuna benzer özellikler gösteriyor ancak sıcaklıklarda çalışma akışkanı olarak su kullanılmasındaki buharlaşma sıcaklığp1 düşerken nanoakışkan kullanılan 1S1 borusundaki buharlaşma sıcaklığı yükselmektedir. Bu da 1 sıl direnci $45^{\circ}$ ye göre artırmaktadır.

Yapılan deneysel çalışmada ölçülen sıcaklık, 1sı yükü, ve soğutma suyu debisine göre hesaplanan 1sı borusu verim değerleride her iki eğim açısındaki 1sı borusu için Eş.2'ye göre hesaplanarak Şekil 10 ve Şekil 11 'de verilmiştir. Şekil 11'de görüleceği üzere 1s1 borusunun performansinda $75^{\circ}$ eğimli 1sı borusunda nanaoakışkan kullanımının 7,5 g/s soğutma suyu debisinde, 300 ve $500 \mathrm{~W}$ isı yüklerinde 1 sıl verimi önemli bir miktarda artırdığ 1 görülmektedir. Isıl verim 300W için \%85'lerden \%95'lere çıkarken 500 W 1s1 yükünde \%70'lerden \%98'lere çıkmaktadır. Farklı soğutma suyu debileri ile farklı isı yüklerinde çalışma akışkanının nanoakışkan ile kıyaslanması ise Şekil 12'de verilmiştir.

Çalışmanın sonuçları irdelendiğinde nanoakışkan kullanımının 1sı borusunun ısıl direncini azalttığı ve termal verimi artırdığı gözlenmiştir.

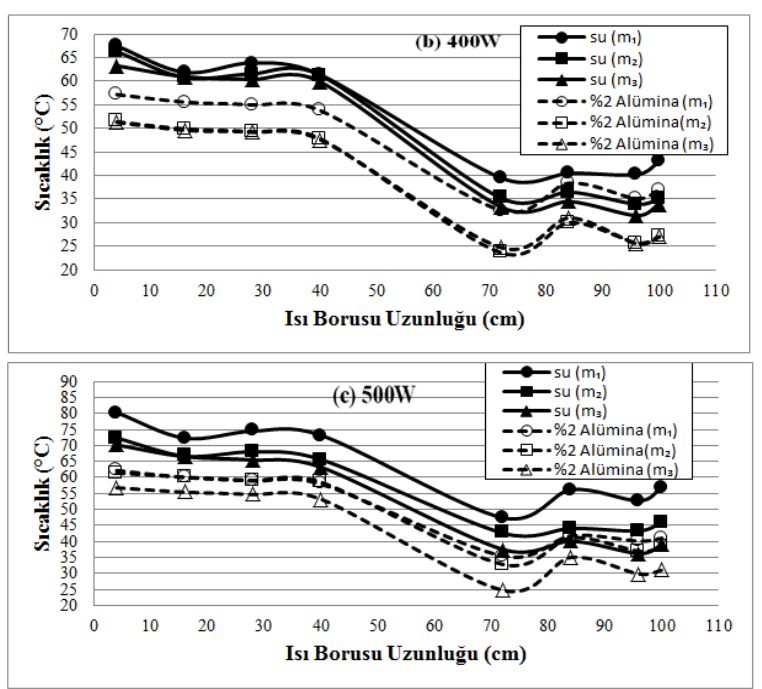

Şekil 9. (a-c) Nanoakışkan ve saf su kullanılan $75^{\circ}$ lik eğime sahip 1sı borusunun belirli noktalarından ölçülen ortalama sıcaklıkların karşılaştırılması ((ac)Comparison of mean temperature measuring from specific point in heat pipe having $75^{\circ}$ slope, using nano-fluid and water) 


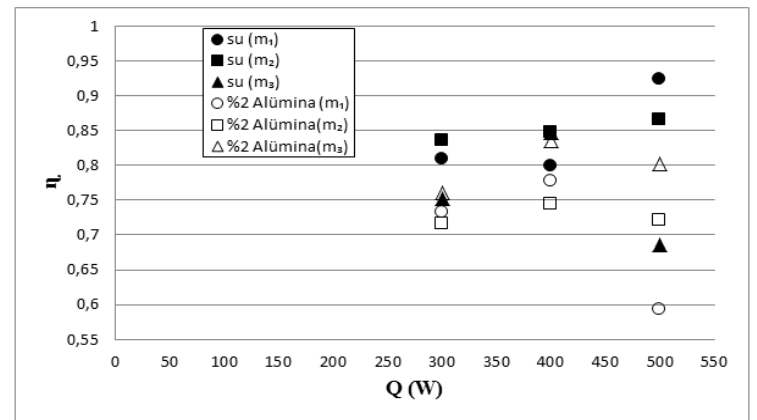

Şekil 10. Nanoakışkan ve saf su kullanılan $45^{\circ}$ lik eğime sahip 1s1 borusunun verimlerinin karşılaştırılması (Comparison of effectiveness of heat pipe having $45^{\circ}$ slope, using nano-fluid and water)

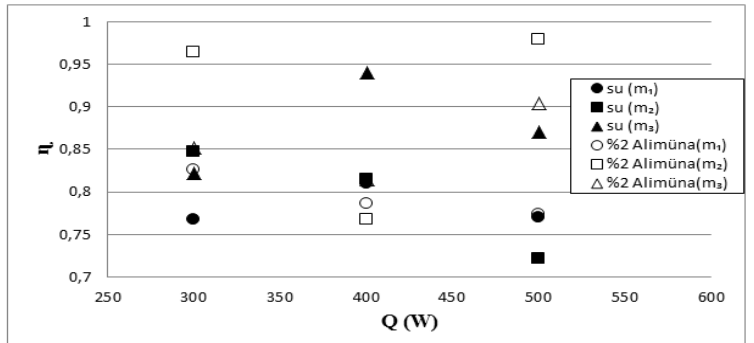

Şekil 11. Nanoakışkan ve saf su kullanılan $75^{\circ}$ lik eğime sahip 1s1 borusunun verimlerinin karşılaştırılması (Comparison of effectiveness of heat pipe having $45^{\circ}$ slope, using nano-fluid and water)

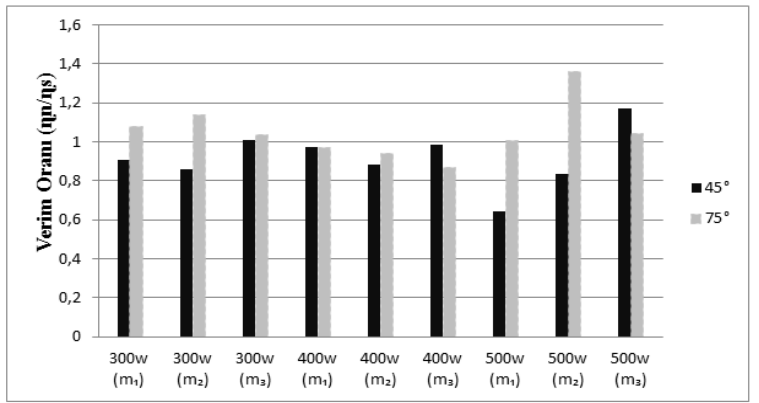

Şekil 12. $45^{\circ}$ ve $75^{\circ}$ yapılan deneylerde; Nanoakışkan verimlerinin saf su verimlerine göre karşılaştırılması (Comparison of nano-fluid efficiency with respect to pure water efficiency, on testing making at $45^{\circ}$ and $75^{\circ}$ angle)

\section{SONUÇLAR VE ÖNERÍLER (RESULTS AND RECOMMENDATIONS)}

Hareketli parçalarının bulunmaması büyük miktarlardaki 1sıyı aktarabilmesi gibi birçok özelliğinden dolayı 1sı boruları çeşitli uygulamalarda kullanılmaktadır. Is1 borularının performanslarının iyileştirilmesi üzerine gerek geometrik, gerek yapısal ve gerekse çalışma akışkanları üzerine yoğunlaşılan çalışmalar mevcuttur. Bu çalışmada 1sı borusunda kullanılan çalışma akışkanının içerisinde nano boyutta partiküller içeren metal oksit kullanılmasıyla isıl performansının iyileştirilmesine katkı amaçlanmıştır. $\mathrm{Bu}$ doğrultuda literatürde nanoakışkanların en büyük sorunu olan çökelme ve topaklanmayı engelleyen bir yüzey aktifleştirici kullanılmış ve performans deneyleri gerçekleştirilmiştir. Böylece 1sı borusunun ısıl direncini düşürmek, düşük sıcaklık farklarında 1sı iletim miktarını arttırmak ve 1sı borusu performansını arttırmak amaçlanmıştır.

Yapılan deneyler sonucu elde edilen verilere göre 1s1 dirençte önemli düşüşler elde edilmiş 1 sıl verim değerlerinde tam bir stabilizasyon sağlamazken; $500 W^{\prime} l ı k$ giriş gücünde, $0,0075 \mathrm{~kg} / \mathrm{s}^{\prime}$ lik kütlesel debide ve $75^{\circ}$ 'lik 1sı borusu eğiminde nanoakışkan ile yapılan deneyde, aynı veriler için, su ile yapılan deneye göre \% 35,7 verim iyileştirilmesi elde edilmiştir.

\section{KISALTMALAR}

$C_{p} \quad$ Özgül 1sı kapasitesi, $\left(\mathrm{kj}_{\mathrm{kg}} \mathrm{g}^{-1} \mathrm{~K}^{-1}\right)$

$\dot{m} \quad$ Kütlesel debi, $\left(\mathrm{kg} \mathrm{s}^{-1}\right)$

$\mathrm{R}$ Isıl direnç, $(K / W)$

$\dot{Q} \quad$ Isı yükü, $(W)$

$\mathrm{T} \quad$ Sicaklık, $(K)$

$\Delta \mathrm{T}$ Sicaklık farkı, $(K)$

\section{ALTINDISLER}

$\begin{array}{ll}\mathrm{c} & \text { Kondenser } \\ \mathrm{e} & \text { Evaporatör } \\ \mathrm{HP} & \text { Heat pipe } \\ \text { in } & \text { Kondenser soğutma suyu girişi } \\ \mathrm{nf} & \text { nanoakışkan } \\ \text { out } & \text { Kondenser soğutma suyu çıkışı } \\ \mathrm{p} & \text { partikül } \\ \text { w, water } & \text { Deionized water }\end{array}$

\section{KAYNAKLAR (REFERENCES)}

1. "Is1 Borusu İle CPU Soğutulması", Atatürk Üniversitesi Meslek Seçmeli II Dönem Projesi, 2011.

2. Seven, M., Isı Borusunun Yalıtılmış Bölgesindeki Akının Analitik Olarak İncelenmesi, Yüksek Lisans Tezi, İstanbul Teknik Üniversitesi Enerji Enstitüsü, İstanbul, 2007.

3. Genceli, O.F., "Is1 Borusu", İ.T.Ü. Makine Fakültesi Isı Tekniği ve Ekonomisi Araştırma Enstitüsü Bülteni, 1-29, 1976.

4. Huminic, G., Huminic, A., Morjan, I., Dumitrache, F., "Experimental study of the thermal performance of thermosyphon heat pipe using iron oxide nanoparticles", International Journal Of Heat And Mass Transfer, Cilt 54, No 1, 656-661, 2011.

5. Şahin, B., Çomaklı, K., Çomaklı, Ö., Yılmaz, M., Karslı, S., Özyurt, Ö., Karagöz, Ş., Kaya, M., "Nanokışkanların Isı Transferi ve Akış Karakteristiklerinin İncelenmesi”, Tübitak, Proje No: 105M292, 2010.

6. Sureshkumar, R., Mohideen, S., T., Nethaji, N., "Heat transfer characteristics of nanofluids in heat pipes: Areview", Renewable and Sustainable Energy Reviews, Cilt 20, 397-410, 2013.

7. Choi, J.A., "Eastman, Enhancing thermal conductivity of fluids with nanoparticles, in: D.A. 
Siginer, H.P. Wang (Eds.)", Developments and Applications of Non-Newtonian Flows, ASME, 99-105, 1995.

8. Zhen, H.L., Yuan, Y.L., "A New Frontier of Nanofluid Research - Application of Nanofluids in Heat Pipes", Intenational Journal of Heat and Mass Transfer, Cilt 55, 6786-6797, 2012.

9. Chien, H.T., Tsai, C.Y., Chen, P.H., Chen, P.Y., "Improvement on thermal performance of a diskshaped miniature heat pipe with nanofluid", Proceedings of the Fifth International Conference on Electronic Packaging Technology, IEEE,389-391, 2003.

10. Wei, W.C., Tsai, S.H., Yang, S.Y., Kang, S.W., "Effect of nano-fluid concentration on heat pipe thermal performance", IASME Trans. 2 14321439, 2005.

11. Kang, S.W., Wei, W.C., Tsai, S.H., Yang, S.Y., "Experimental investigation of silver nano-fluid on heat pipe thermal performance", Appl. Thermal Eng. Cilt 26, 2377-2382, 2006.

12. Liu, Z.H., Lu, L., "Thermal performance of axially microgrooved heat pipe using carbon nanotube suspensions", J. Thermophys Heat Transfer, Cilt 23, 170-175, 2009.

13. Yang, X.F., Liu, Z.H., Zhao, J., "Heat transfer performance of a horizontal microgrooved heat pipe using $\mathrm{CuO}$ nanofluid", J. Micromech Microeng. Cilt 18, 2008.

14. Tsai, C.Y., Chien, H.T., Ding, P.P., Chan, B., Luh, T.Y., Chen, P.H., "Effect of structural character of gold nanoparticles in nanofluid on heat pipe thermal performance", Mater. Lett. Cilt 58, 1461-1465, 2004.

15. Liu, Z.H., Shu, T., "Application of nanofluids in thermal performance enhancement of horizontal screen heat pipe", J. Aerospace Power, Cilt 23, 1623-1627, 2008.

16. Chen, Y.T., Wei, W.C., Kang, S.W., Yu, C.S., "Effect of nanofluids on flat heat pipe thermal performance", Proceedings of the 24th IEEE Semiconductor Thermal Measurement and Management Symposium, IEEE, 16-20, 2008.

17. Kang, S.W., Wei, W.C., Tsai, S.H., Huang, C.C., "Experimental investigation of nanofluids on sintered heat pipe thermal performance", Appl. Thermal Eng., Cilt29, 973-979, 2009.

18. Shang, F.M., Liu, D.Y., Xian, H.Z., Yang, Y.P., Du, X.Z., "Flow and heat transfer characteristics of cifferent forms of nanometer particles in oscillating heat pipe", J. Chem. Indust. Cilt 58, 2200-2204, 2007.

19. Qu, J., Wu, H.Y., Cheng, P., "Thermal performance of an oscillating heat pipe with A12O3-water nanofluids", Int Commun Heat Mass Transfer, Cilt 37, 111-115, 2010.

20. Xue, H., Fan, J., Hu, Y., Hong, R., Cen, K., “The interface effect of carbon nanotube suspension on the thermal performance of a two-phase closed thermosyphon", J. Appl. Phys, Cilt 100, 2006.
21. Liu, Z.H., Yang, X.F., Guo, G.L., "Effect of nanoparticles in nanofluid on thermal performance in a miniature thermosyphon", $\mathbf{J}$. Appl. Phys., Cilt 102, 2007.

22. Liu, Z.H., Yang, X.F., Wang, G.S., Guo, G.L., "Influence of carbon nanotube suspension on the thermal performance of a miniature thermosyphon", Int. J. Heat Mass Transfer, Cilt 53, 1914-1920, 2010.

23. Khandekar, S., Joshi, Y., Mehta, B., "Thermal performance of closed two-phase thermosyphon using nanofluids", Int. J. Thermal Sci., Cilt 47, 659-667, 2008.

24. Naphon, P., Assadamongkol, P., Borirak, T., "Experimental investigation of titanium nanofluids on the heat pipe thermal efficiency", Int. Commun. Heat Mass Transfer, Cilt 35, 1316-1319, 2008.

25. Noie, S.H., Heris, S.Z., Kahani, M., Nowee, S.M. "Heat transfer enhancement using A12O3/water nanofluid in a two-phase closed thermosyphon", Int. J. Heat Fluid Flow , Cilt 30, 700-709, 2009.

26. Çıkın, A., "Isı boruları", Yüksek Lisans Tezi, İ.T.Ü. Fen Bilimleri Enstitüsü, İstanbul, 1988.

27. Alt, N.," Tek Kanallı Isı Borusu İle Çok Kanallı Isı Borusu Verimlerinin Karşılaştırılması", Yüksek Lisans Tezi, Karabük Üniversitesi Fen Bilimleri Enstitüsü, Karabük, 2010.

28. Yüksel, T., "Soğutucu Akışkanların Kullanıldığı Isı Borulu Güneş Kolektörünün Kullanabilirliğinin Deneysel ve Teorik Olarak Araştırılması”, Yüksek Lisans Tezi, Fırat Üniversitesi Fen Bilimleri Enstitüsü, Elazı̆̆, 1998.

29. Ong, K.S., Haider-E- Alahi, M., "Performance of a R-134A filled thermosyphon", Applied Thermal Engineering, Cilt 23, 2373-2381, 2003.

30. Feldman, K.T. and Whiting, G.H., "Applications of the Heat Pipe", Mechanical Engineering, Cilt 90, 48-53, 1968.

31. Touloukian Y. S., Powell R. W., Ho C. Y., and Klemens, P. G., "Thermophysical Properties of Matter”, Plenum Press, New York ,Cilt 2, 1970.

32. Choi, S. U. S., Zhang Z. G., Yu, W., Lockwood, F. E. and Grulke, E. A., "Anomalously Thermal Conductivity Enhancement in Nanotube Suspensions". Applied Physics Letters, Cilt 79, 2252-2254, 2001.

33. Wang X., Mujumdar A.S., "Heat Transfer Characteristics of Nanofluids: A Review", International Journal of Thermal Sciences, Cilt 46, 1-19, 2007.

34. Xuan Y., Li Q., "Heat Transfer Enhancement of Nanofluids", International Journal of Heat and Fluid Flow, Cilt 21, No 1, 58-64, 2000.

35. XuanY., Li Q., Hu W., "Aggregation Structure and Thermal Conductivity of Nanofluids", AIChE Journal, Cilt 49, No 4, 1038-1043, 2003. 